التباده البراججي التلغزيوني بينه دول العالم الإسلامي

\title{
التبادل البرامجي التلفزيوني بين دول العالم الإسلامي وأهميته في الإرشاد
}

\section{والتلدربب لحجاج بيث الله الحرام}

دراسة مسحية استطلاعية للاعاة والمختصين في السودان 2019م د.أحمد إسماعيل حسين محمد ".

$$
\text { مستلخص البحث: }
$$

يعتبر الإعلام التلفزيوني الفضائي أقوى وسائل الإعلام تأثنيراً على المتلقي حسب العديد من الدراسات، وهذه الميزة برزت في مختلف الميادين والمجالات التي تتاولها الإعلام التلفزيوني، غير أنها في نظر الباحث لم توظف بالقدر الكافي توظيفاً نوعياً في مجال إرشاد الحجاج وإحاطتهم بمناسك الحج، في الوقت الذي لا يزال بعض الحجاج يرتكب

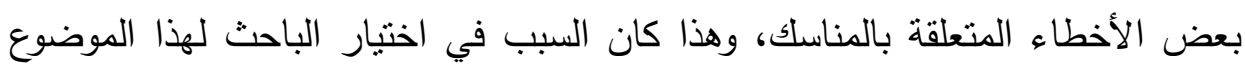
لتحقيق بعض الأهداف التي نتمنل في حث الفضائيات التلفزيونية في الدول العربية والإسلامية على وجه الخصوص وبقية دول العالم التي لا تخلو من أقليات مسلمة، على لى لعب دور إعلامي يتمثل في إنتاج برامج تلفزيونية متخصصة في التدريب والتوعية بمناسك الحج، بأساليب جاذبة وشيقة تسهم في تعليم الحجاج وتعينهم على أداء تلك المناسك بإتقان، على أن يتم تبادل تلك البرامج (Programme exchange) مابين الفضائيات في الدول المعنية لتوسيع نطاق المنفعة والاستفادة لدى المستهدفين ولتقليل الكلفة الإنتاجية، واتبع الباحث المنهجين الوصفي والتاريخي، واستخدم أداتي الملاحظة

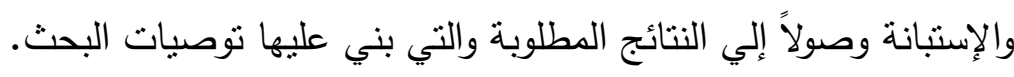
فقام بتقسيم بحثه إلى خمسة مطالب، المطلب الأول عبارة عن الإطار المنهجي للبحث، والمطلب الثاني جاء بعنوان سمات وخصائص الفضائيات التلفزيونية، والمطلب الثالث يتحدث عن التبادل البرامجي التلفزيوني، والمطلب الرابع يتتاول مناسك ومراحل الحج، المطلب الخامس عبارة عن إجراءات الدراسة التطبيقية، ويشتمل على النتائج والتوصيات وقائمة المصادر والمراجع · * أستاذ الإعلام الإكتروني الشارك بكلية الإعلام - جامعة غرب كردفان. 


\section{د. أخدر إسماعبله حسين}

\section{Abstract}

Satellite TV channels, are considered as most powerful media affection on the audience, according to some studies, and this advantage appeared in various fields and areas covered by TV media, according to the researcher did not employ a qualitative employment in the field of guerdoning pilgrims and to teaching them Pilgrimage rituals, while Some pilgrims perform some mistakes related to the rituals. This is why the researcher chose this subject to achieve some of the goals which is to encourage satellite TV channels in Islamic and Arab countries in particular and the rest world countries has minority of Muslim to play a role in the production of TV programs specialized in raising awareness and guidance in the rituals of Pilgrimage in attractive and interesting ways that contribute to teaching pilgrims how to do rituals well, and exchange these programs between satellite channels in the targeted countries to expand the benefit area to the targeted audience And to reduce the cost of production, the researcher followed descriptive and historical methods and used the tools of observation and questionnaire to find results on which recommendations will be based on.

Then divided his research into five demands, the first requirement is the framework of the systematic research, and the second one entitled features and characteristics of satellite TV channels

The third one is about the television exchange programme, The fourth one deals with the rituals of Pilgrimage, The fifth one is the applied study and includes the findings, recommendations, list of sources, references.

الثعور بمشكلة ما للبحث يحدث بصورة تلقائية ويكون دافعاً يثير الباحث للاهنمام بمشكلة ما ويعمل على متابعتها ومحاولة كثفها(1)، أما مشكلة هذا البحث ترتبط

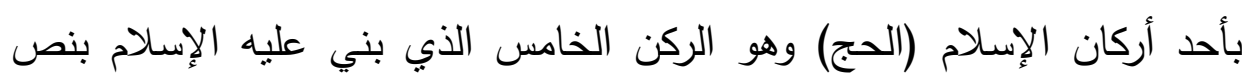
الحديث النبوي الثريف، ولأهميته يتدافع المسلمون لأدائه رغم الكلفة الباهظة، غير عابيين بالتيسير المبني على الاستطاعة كما جاء في الآية الكربمة (وَللَّلَهِ عَلَى

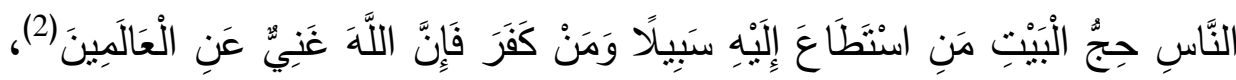
غير أن الباحث يلاحظ بأن بعض الحجاج يعانون كثيراً في أداء مناسك الحج

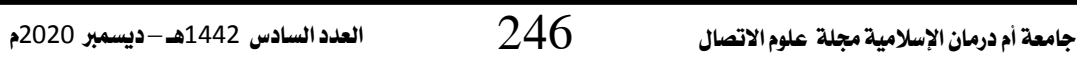




\section{التباده البراججي التلغزيوني بينه دول العالم الإسلامي}

بصورة صحيحة، ومنهم من يرنكب بعض الأخطاء في ذلك،ومن خلال هذه الملاحظة نبعت مشكلة هذا البحث التي عكف الباحث على دراستها محاولاً تقديم رؤية علمية تحمل بعض الحلول لهذه المشكلة البحثية. أهداف البحث:

الهدف النهائي للعلم هو فهم العالم من حولنا، ويقصد بالفهم من وجهة نظر العلم القدرة علي وصف الظاهرة وصفاً دقيقاً وتفسيرها، ومن ثم إمكانية التبؤ بالأحداث، وبمعني آخر فإن الفهم العلمي يعمل على تحقيق أربعة أهداف خاصة هي الوصف، التفسير ، التتبؤ والسيطرة(1)، أما هذا البحث يهذف لتحقيق الآتي: 1- كثـف المعوقات التي تحول دون قيـام الفضـائيات التلفزيونيـة العربيـة بإنتاج برامج تبادل تلفزبوني تعنى بإرشاد وتدريب الحجاج على أداء مناسك الحج. 2- محاولة تقديم رؤى جديدة تسهم في تقديم حلول لمشكلة هذا البحث . 3- تشـجيع التعـاون والتكامـل بين الفضـائيات العربيـة في مجـال التبـادل النـوعي للبرامج 4- مساعدة الحجاج وتدربيهم بأساليب شيقة على أداء مناسك الحج دون أخطاء. 5- لفت نظـر البـاحثين والمختصـين بالإنتاج البرامجي التلفزيـوني لهذا المجـال الهام. أهمية البحث: تكمن أهمية البحث في أنه يتعلق بأداء أحد أركان الإسلام (الحج). تساؤلات البحث: 1- ما جدوى فكرة التبادل البرامجي الخاص بتدريب الحجاج بين القنوات العربية؟.

2- كيف يمكن تعزيز دوافع القنوات العربية وإقناعها بتبني هذه الفكرة ؟. 3- كيف يمكن توظيف ميزات التلفزيون لتعميق أثز التدريب البرامجي على الحجاج؟. 4- ما الفوائد المباشرة التي تتعكس على الفضائيات العربية بتبني هذه الفكرة؟. منهج البحث: 


\section{د. أخد إسماعبله حسبن}

المنهج الأساسي المستخدم في هذا البحث هو الـنهج الوصفي، ويعرف بأنـه الدنهج الذي يصف ظاهرة بغرض الوصول إلى أسبابها والعوامل التي تتحكم فيها

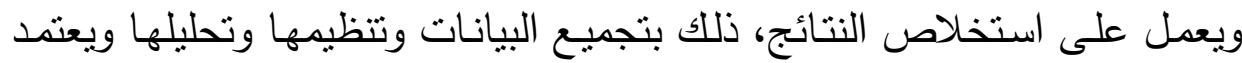

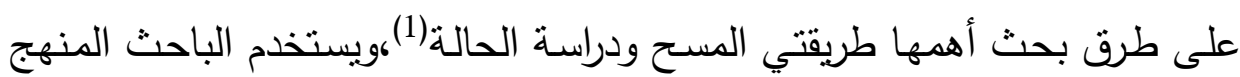

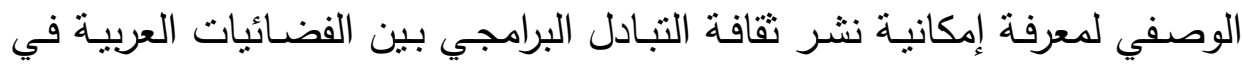

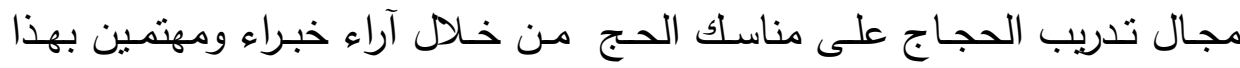

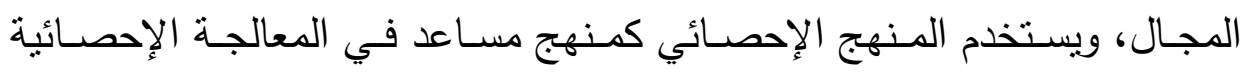

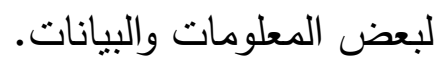

أدوات البحث: يستخدم الباحث من أدوات البحث العلمي الملاحظة(Observation)،

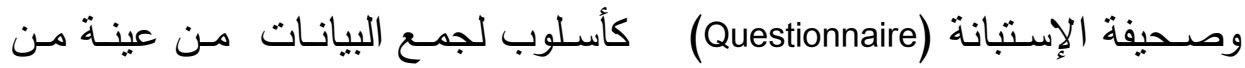

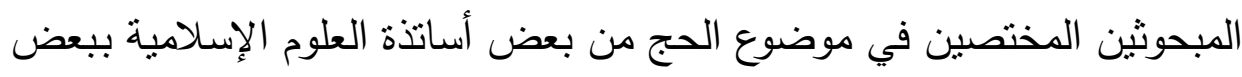

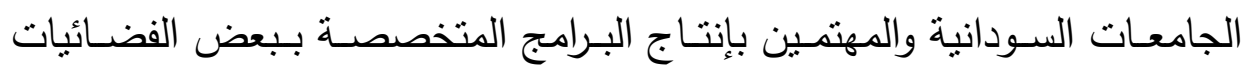

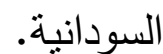

طرق البحث: تستخدم في هذا البحث طريقة دراسة الحالة (Case study) فهي التي تتسق مع طبيعة الموضوع. مجالات البحث (البشري، المكاني، والزماني)

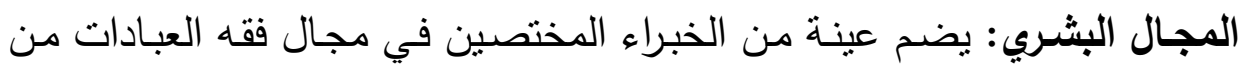

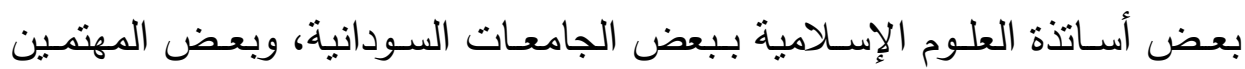
بإنتاج البرامج المتخصصة ببعض الفضائيات السودانية.

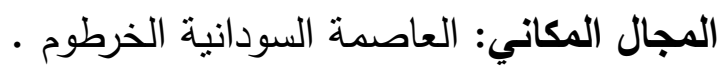
المجال الزماني: 5 أكتوبر 2018م -5 يناير 2019م 


\section{التباده البراججي التلغزيوني بينه دول العالم الإسلامي}

المطلب الثاني: سمات وخصائص الفضائيات التلفزيونية. الفضاء لغة هو ما اتسع من الأرض والخالي من الأرض وما بين السماء والأرض(1) الفضائية Satellite TV Channel هي قناة تلفزيونية عادية تنطلق هن الاهوصن من قاعدة شبيهة بالأستوديو التلفزيوني العادي ولكنها بدلاً من أن تتجه إلى جهاز الإرسال الأرضي فإنها تتجه عبر الوصلة الأرضية الرافعة (Uplink) إلى القناة القمرية (Transponder) في القمر الاصطناعي المعين (2)إن الباحث يتفق مع الإنيانه التعريف السابق ويضيف أن الفضائية هي القناة التلفزيونية التي يستقبلها المشاهد من مؤسسة تلفزيونية عالمية أو إقليمية أو محلية ويبث إرسالها عبر أقمار الاتصالات ويكون استقبالها إما غير مباشر بأسلوب الاستقبال الفضائي وإعادة البث عبر جهاز الإرسال التلفزبوني المحلي (TV transmitter) على المستوى مبلى المحلي، أو مباشر بواسطة طبق مخصص لذلك وجهاز استقبال على المستوى الإى العالمي أو الإقليمي. أو المبنري أما البث التلفزيوني T.V Transmission فيعود إلى العالم الأمريكي (فلادمير زوركين) وهو من أصل روسي قدم عرضاً خلال 1934م- 1939م لنظام ، Iconoscope تلفزبوني الكتروني باستخدام أنبوب كاميرا أسماه (إيكونوسكوب) وبدأ الإرسال العادي للتلفزيون (3)واستمرت جهود التطوير بالتركيز على العناصر الإلكترونية وزيادة عدد الخطوط Scanning Lines المكونة للصورة التلفزيونية NTSC في الثانية لخلق نوع من التوافق بين الأنظمة التلفزبونية الثلاث الأمريكي 1953م والأوروبيين بال Pal وسيكام 1975 Secam لتحقيق إمكانية الاستقبال المتبادل بين هذه الأنظمة الثلاثة دون عيوب فنية في الصورة(4)ومن أهم خصائص القنوات الفضائية التلفزيونية أنها تجمع بين الصورة المتحرّكة والحديث الصوتيّ، تتقل الأحداث بصورتها الفعليّة، ولها القدرة على التأثير في الرأي العام ومخاطبته، والسرعة الكبيرة في نقل الأخبار والأحداث، حتى تصل إلى كافة الناس 


\section{د. أخد إسماعبله حسبن}

في أية بقعة من العالم بالدجان، وتقدم مختلف أساليب الترفيه والتسلية، ولها القدرة

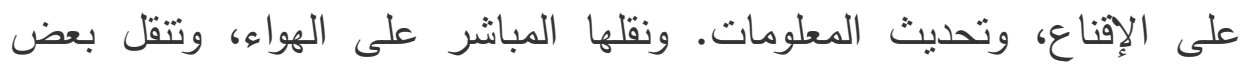

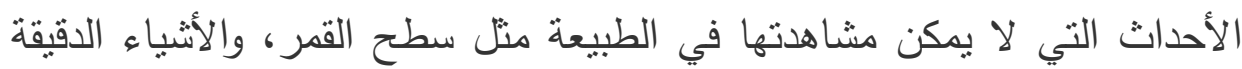

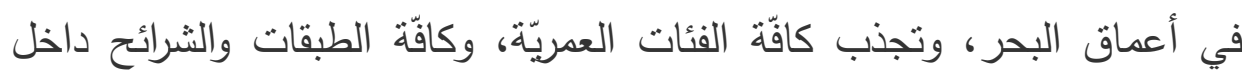

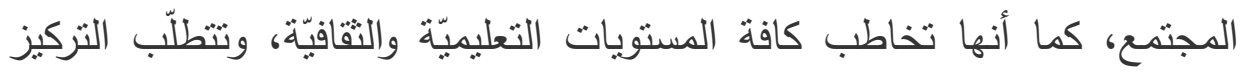
والتفرغ لمتابعتها لأنها تخاطب حاسة البصر وحاسة السمع. وتجعل العالم بين

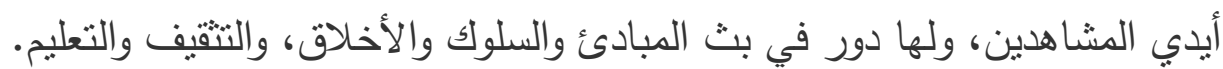

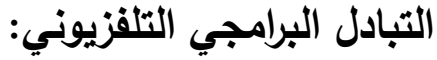

حدثت نقلة هائلة في مجال التبادل البرامجي التلفزيوني بفضل نظام الاتّصال لإتحاد إذاعات الدول العربية للتّبادل متعدّد الوسائط والخدمات التهات عبر الأقمار الاصطناعية (MENOS-ASBU) وهو من أحدث الأنظمة عالمياً في مجال

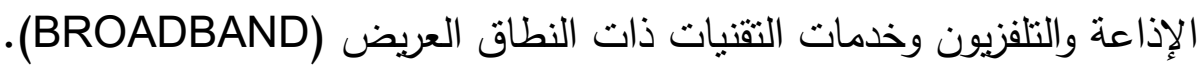
ويعتمد هذا النظام استخدام التقنيات الأحدث عالمياً في مجالات الاتصال وفي

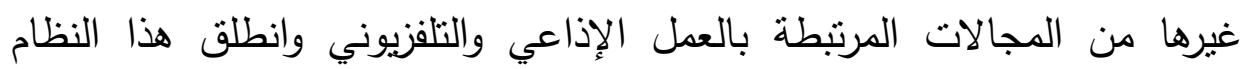

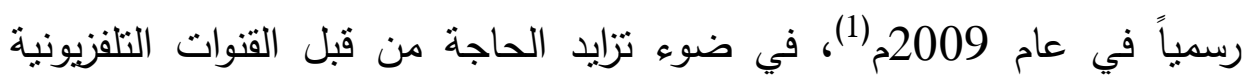

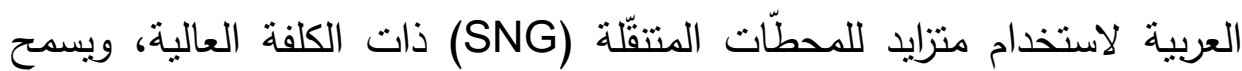
النظام ببث مادة فيديو حبة عبر المحطة الرئيسية بجودة عالية، كما يمكن إرسال

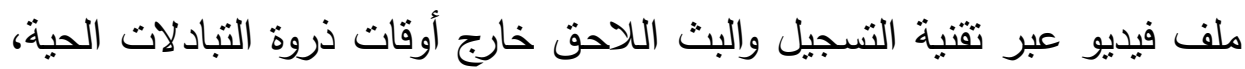

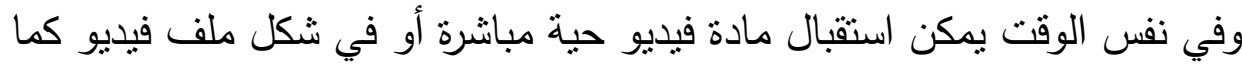

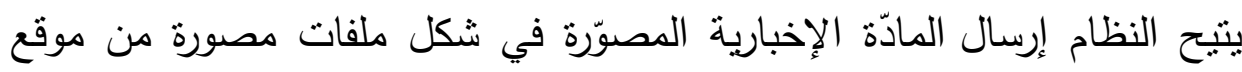

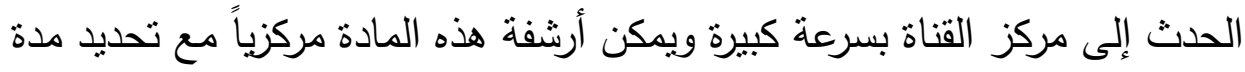
التخزين (قصير ، متوسط ، طويل) واسترجاعها لاحقاً (2). 


\section{البّاده البرابجي التلغزيوني بينه دول العالم الإسلامي}

ومن مميزات التبادل البرامجي التلفزيوني بين القنوات الفضائية أنه يوفر الكلفة الإنتاجية للبرامج بصورة كبيرة ويمتاز بالتجويد من حيث الإنتاج وأساليب العرض ين كتحدي مطلوب لسعة الانتشار التي تتحقق من خلال جميع القنوات الناقلة للعمل التلفزيوني، ويعزز تبادل الآراء والخبرات من خلال الماحظات التي تقدم من مختلف المختصين، ويعمل على خلق نوع من التكامل مابين العديد من المؤسسات التلفزيونية بالوطن العربي. شعائر الحج: الحج هو الركن الخامس الذي بني عليه الإسلام بنص الحديث الثريف، عن أبي عبد الرحمن عبد الله بن عمر بن الخطاب رضي الله عنهما قال : سمعت رسول الله صلى الله عليه وسلم يقول:بني الإسلام على خمس: شهادة أن لا إله إلا الله، وأن محمداً رسول الله، وإقام الصلاة، وإيتاء الزكاة، وحج البيت، وصوم الإنه رمضان(رواه البخاري ومسلم(1)، وقد وردت كلمة الحج في العديد من الآيات القرآنية ومنها:

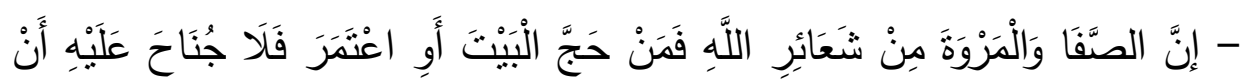

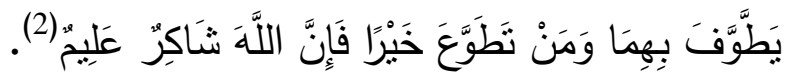

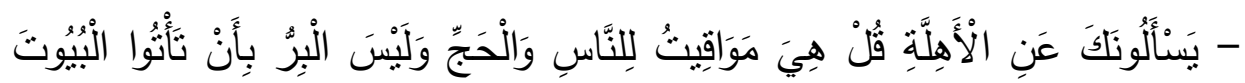

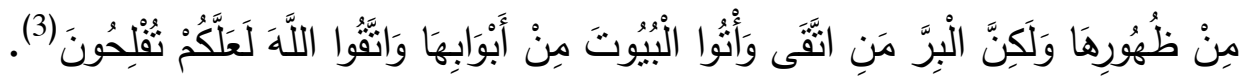

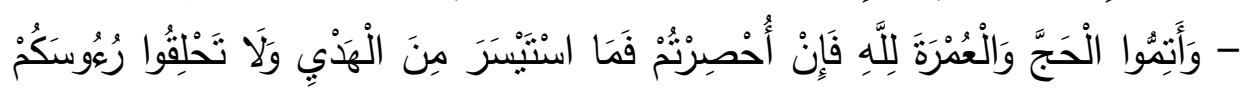

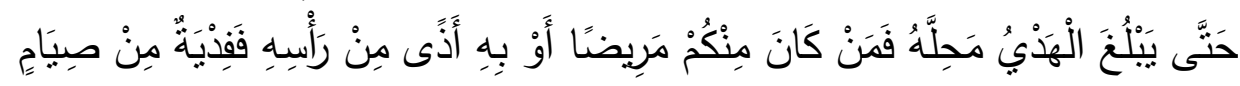

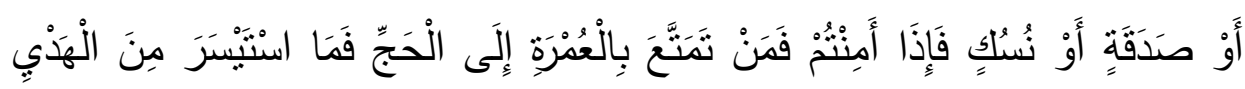

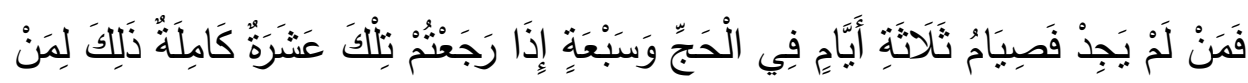

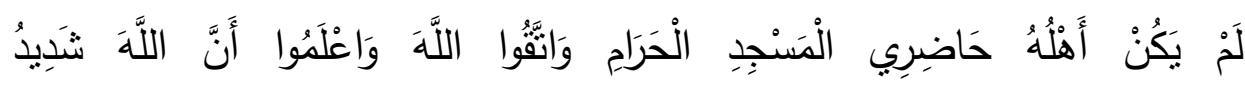

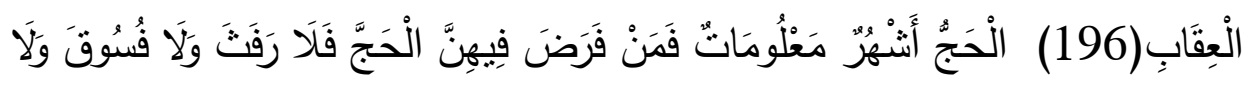




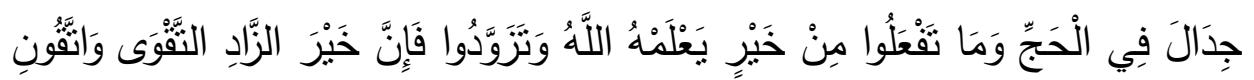

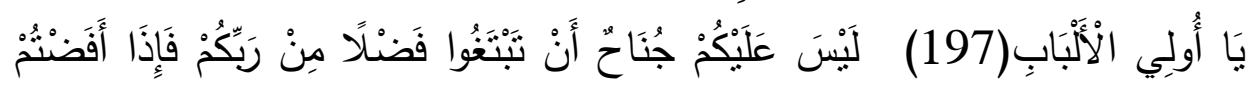

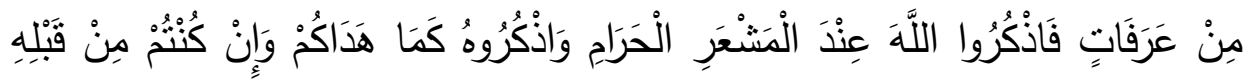

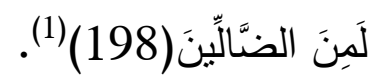

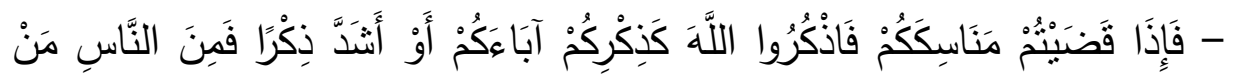

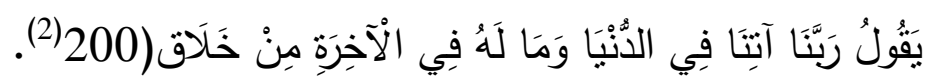

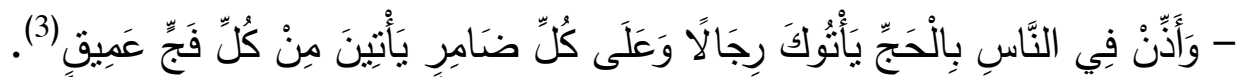

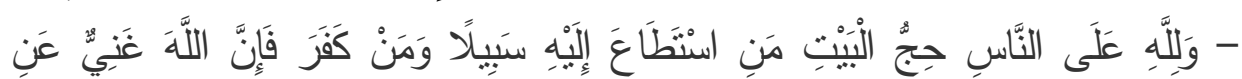

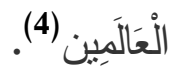
مراحل الحج: يتنقل الحجاج أثناء أدائهر لمناسك الحجج من مرحلة إلى أخرى، وفي كل مرحلة

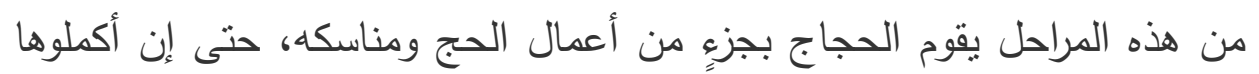

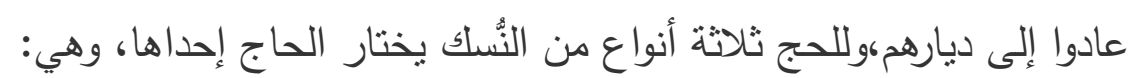
حج القِران: وهو أن يحرم الحاج بالعمرة والحج معاً، فيقرن بينهما.

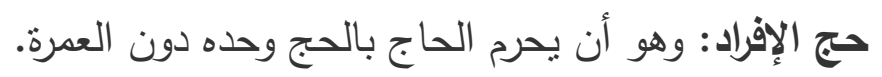

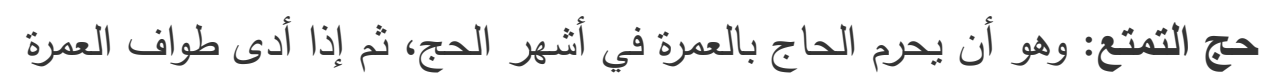
وسعى سعيها، أحرم بالحج من مكانه. أما المراحل التي تمر بها مناسك الحج فهي منتابهة، ويمكن تلخيصها كما يلي:

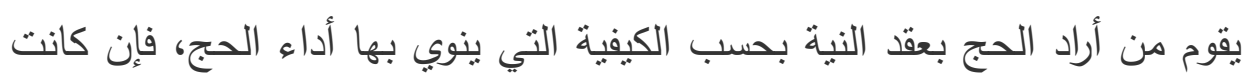

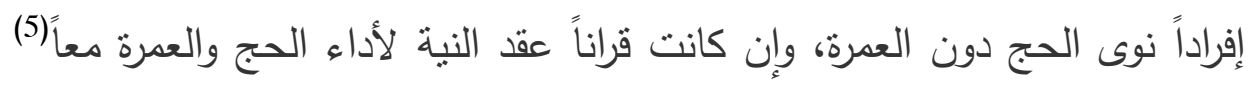

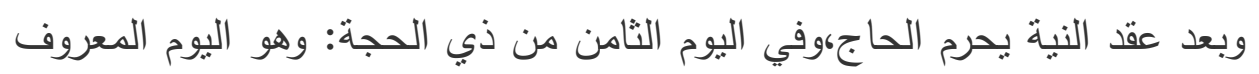

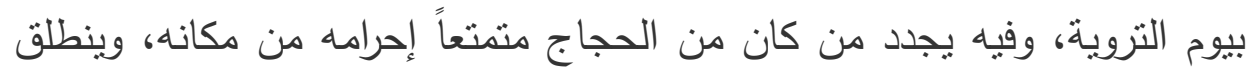

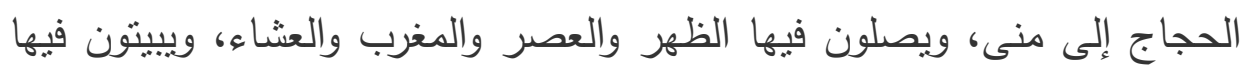




\section{البّاده البرابجي التلغزيوني بينه دول العالم الإسلامي}

ويؤدون صلاة فجر اليوم التاسع من ذي الحجة فيها قبل مغادرتهاهوفي اليوم التاسع من ذي الحجة وهو اليوم المعروف بيوم عرفة، ينطلق الحجاج بعد أدائهم لصالاة الفجر في منى إلى منطقة جبل عرفة، حتى إذا حل وقت الزوال أي دخول

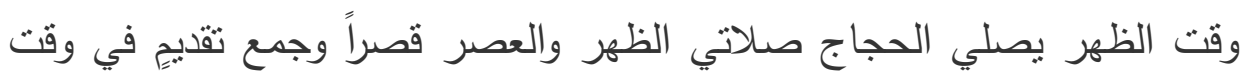
الظهر • ويتوجهون بعدها للوقوف بجبل عرفة، ويستثرون وقوفهم الذي يمتد حتى غروب شمس هذا اليوم بالذكر والدعاء والابتهال إلى الله تعالى، والوقوف بعرفة ركن من أركان الحج التي لا يصح الحج بدونها، ولم تشرق الثمس في يوم أفضل من يوم عرفة(1)، ثم يذهب الحجاج بعد مغيب الثمس إلى مزدلفة، ويصلون فيها صلاتي المغرب والعشاء جمع تأخير في وقت العشاء مع قصرها، وبييتون فيها ليلتهم، لينطلقوا منها بعد صلاة فجر اليوم العاثر، ويستحب للحجاج جمع الحصى من مزدلفة استعداداً لرمي الجمرات في يوم النحر ،وفي اليوم العاشر من ذي الحجة وهو اليوم المعروف بيوم النحر، تتركز في هذا اليوم أكثر أعمال الحج ومناسكه، ويصل الحجاج إلى منى، ويشرعون في رمي جمرة العقبة أو الجمرة الكبرى، وتكون برمي سبع جمراتٍ (حصى) ويكبرون عند كل رمية ويقطعون التلبية عند البدء بالرمي، ثم يقوم الحجاج بذبح الهدي، وهو واجب على الحاج المتمتع والقارن، وسنة في حق سواهما، ثم يتحللون بذللك من إحرامهم التحلل الأول أو الأصغر، فيحل كل ما كان محظوراً عليهم سوى الجِماع، ثم يتوجهون إلى مكة ونة المكرمة لأداء طواف الإفاضة ويسمى طواف الزيارة، ويسعى منهم بين الصفا والمروة من لم يسع عند أول قدومه مكة قبل يوم التروية، ومن بعدها بتحلل الحجاج التحلل الثاني أو الأكبر، ليحل لهم بذلك كل محظور عليهم من وقت إحرامهم بالحج وأثنائه(2)، وفي أيام التشريق الثناثثة وهي أيام الحادي عشر ، والثاني عشر، والثالث عشر من شهر ذي الحِجة وفي كل يوحٍ من هذه الأيام يرمي الحجاج بثلاثثة جمرات هي الجمرة الصغرى، والجمرة الوسطى، والجمرة الكبرى أو ولي 
جمرة العقبة في كل جمرة يرمي بسبع حصيات، والمبيت بِّنى في اليومين الحادي

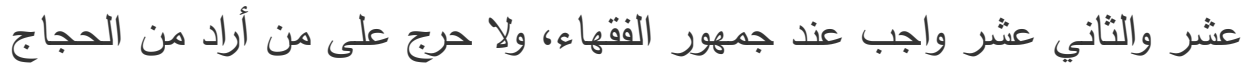

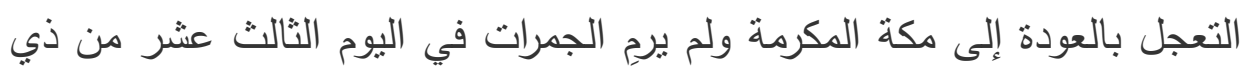

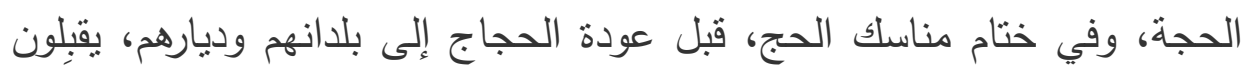

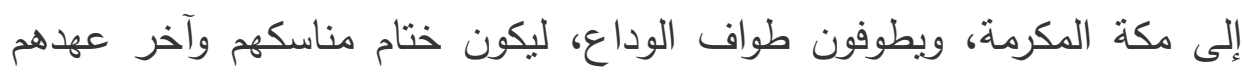
بييت اله الحرام وطواف كعبته المشرفة(1)،

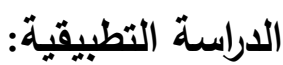

اختار الباحث عينة عمديه للبحث تختص ببعض خبراء فقه العبادات ببعض لإله

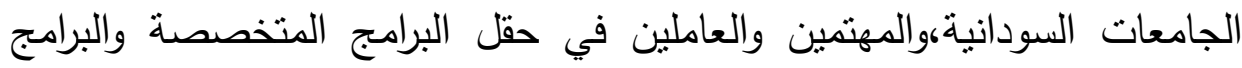
الدينية ببعض القنوات الفضائية السودانية للحصول على آراء أفراد العينة حول كيفية تعزيز وتفعيل التبادل البرامجي التلفزيوني المتخصص بين الفضائيات العربية

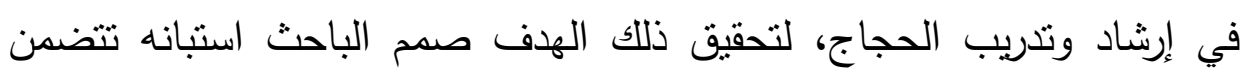

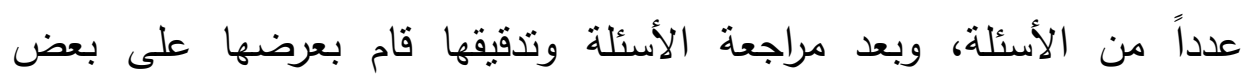
المختصين الأكاديميين لمزيد من التدقيق،ثم قام بتوزيع الإنتبانة على الإنى العينة

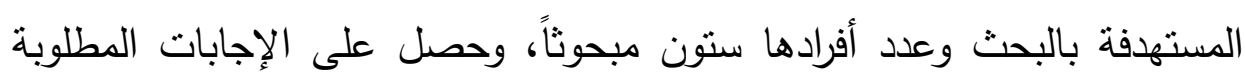

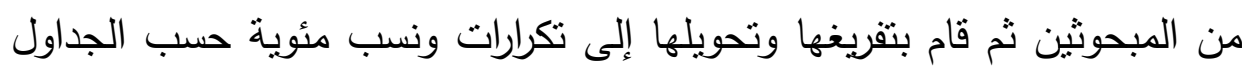
والأثكال البيانية أدناه وذلك على النين النحو التالي: الجدول رقم (1) يبين العينة المبحوثة حسب النوع

\begin{tabular}{|c|c|c|}
\hline النسبة المئوية & التكرار & النوع \\
\hline$\% 66.7$ & 40 & ذكر \\
\hline$\% 33.3$ & 20 & أنثى \\
\hline$\% 100$ & 60 & المجموع \\
\hline
\end{tabular}


التباده البرابجي التلغزيوني بين دول العالم الإسلامي

الثكل رقم (1) يبين العينة المبحوثة حسب النوع

\section{النسبة المئوية حسب النوع}

ذكر س

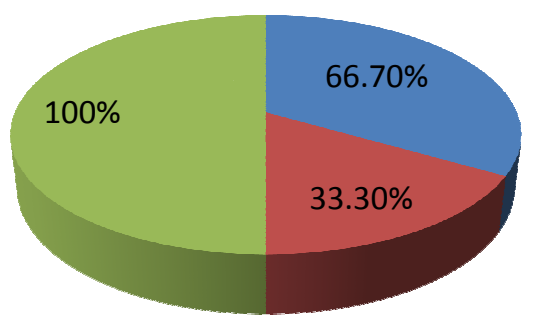

من الجدول والثكل رقم (1) يتضـح أن نسبة الذكور من أفراد العينة هي الغالبة حيث بلغت 66.6\% أما نسبة الإناث فبلغت 33.4\% . الجدول رقم (2) يبين العينة المبحوثة حسب المؤهل العلمي

\begin{tabular}{|c|c|c|}
\hline النسبة المئوية & التكرار & المؤهل العلمي \\
\hline 00 & 0 & دون الجامعي \\
\hline$\% 40$ & 24 & جامعي \\
\hline$\% 60$ & 36 & فوق الجامعي \\
\hline$\% 100$ & 60 & المجموع \\
\hline
\end{tabular}

الشكل رقم (2) يبين العينة المبحوثة حسب المؤهل العلمي

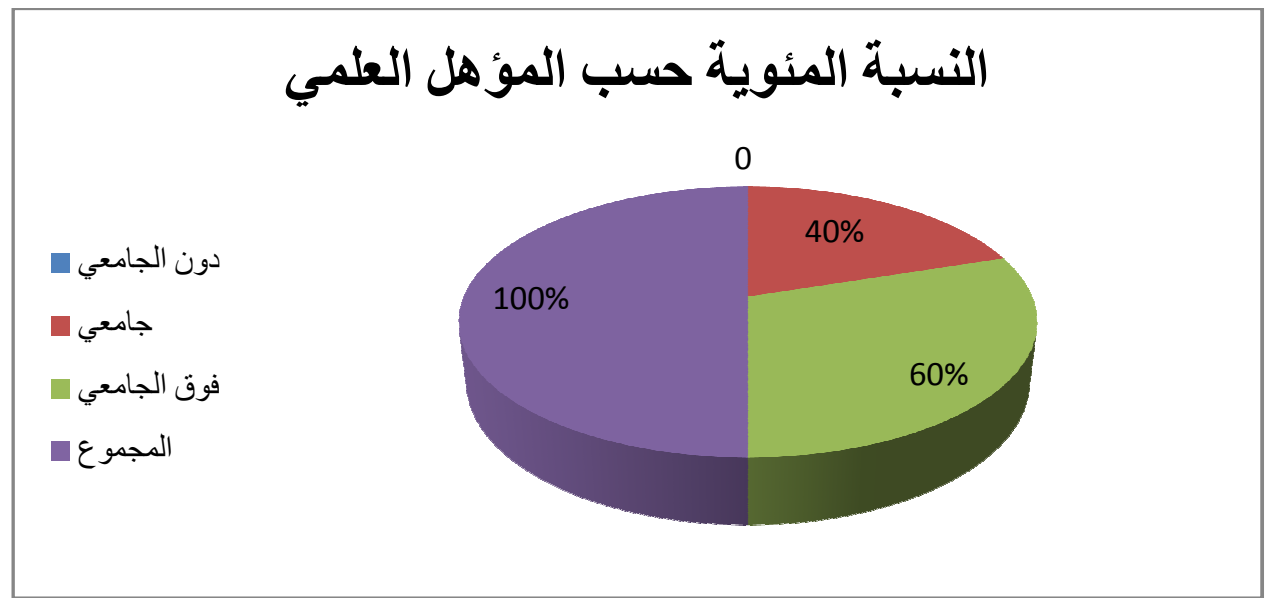




\section{د. أخمد إسماعبل حسين}

من الجدول والثكل البياني رقم(2) يتبين أن الحائزين على مؤهل فوق الجامعي

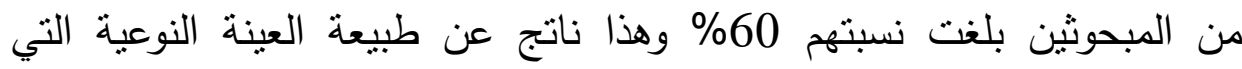

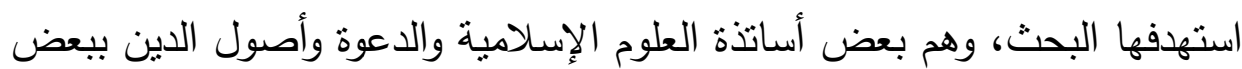
الجامعات السودانية وبعض المختصين في مجال إنتاج البرامج التلفزيونية من البنائ

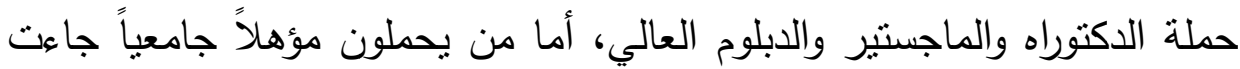
نسبتهم 40\%، ولا يوجد من بين المبحوثين من يحمل مؤهلاً علمياً دون الجامعي.

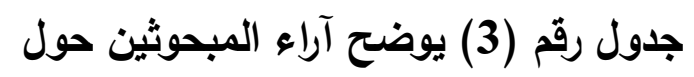

متابعتهم للبرامج الدينية بالقتوات الفضائية العربية

\begin{tabular}{|c|c|c|}
\hline النسبة المئوية & التكرار & مستوى المتابعة \\
\hline$\% 50$ & 30 & أتابع باستمرار \\
\hline$\% 26.6$ & 16 & أتابع أحيانا \\
\hline$\% 16.7$ & 10 & أتابع حسب الظروف \\
\hline$\% 6.7$ & 4 & لا أتابع \\
\hline$\% 100$ & 60 & المجموع \\
\hline
\end{tabular}

شكل رقم (3) يوضح آراء المبحوثين حول متابعتهم

للبرامج الاينية بالقتوات الفضائية العربية أوناء

\section{النسبة المئوية لمستوى المتابعة}

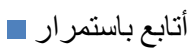

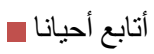

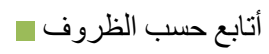

لا لأنابع

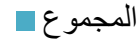

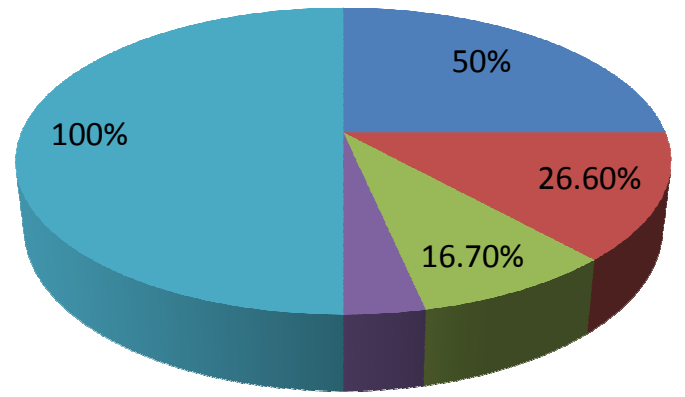

$6.70 \%$ 
التباده البراججي التلغزيوني بينه دول العالم الإسلامي

من الجدول والثكل البياني رقم(3) ينتين أن غالبية المبحوثين ينابعون البرامج

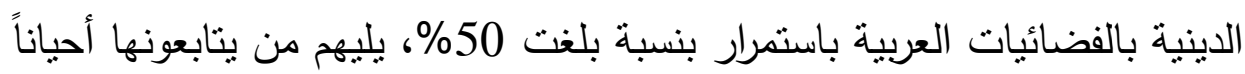
بنسبة 26.6\%، ومن يتابعون حسب الظروف بنسبة 16.7\% ، وهذه المتابعة الكبيرة تعود للعينة النوعية المتخصصة والمهتمة بهذا المجال، أما الذين لا يتابعون

$$
\text { نوقفت نسبتهم عند 6.7\% }
$$

جدول رقم (4) يوضح آراء المبحوثين حول درجة اهتمام البرامج

الاينية بالفضائيات العربية بتوعية الحجاج وتدريبهم على مناسك الحج

\begin{tabular}{|c|c|c|}
\hline النسبة المئوية & التكرار & مستوى الاهتمام \\
\hline$\% 16.7$ & 10 & تهتم بشدة \\
\hline$\% 33.3$ & 20 & تهته إلى حد ما \\
\hline$\% 16.7$ & 10 & غير متأكد \\
\hline$\% 33.3$ & 20 & لاتهتم \\
\hline$\% 100$ & 60 & المجموع \\
\hline
\end{tabular}

جدول رقم (4) يوضح آراء المبحوثين حول درجة اهتمام البرامج

الاينية بالفضائيات العربية بتوعية الحجاج وتدريبهم على مناسك الحج النسبة المئوية لمستوى الإهتمام

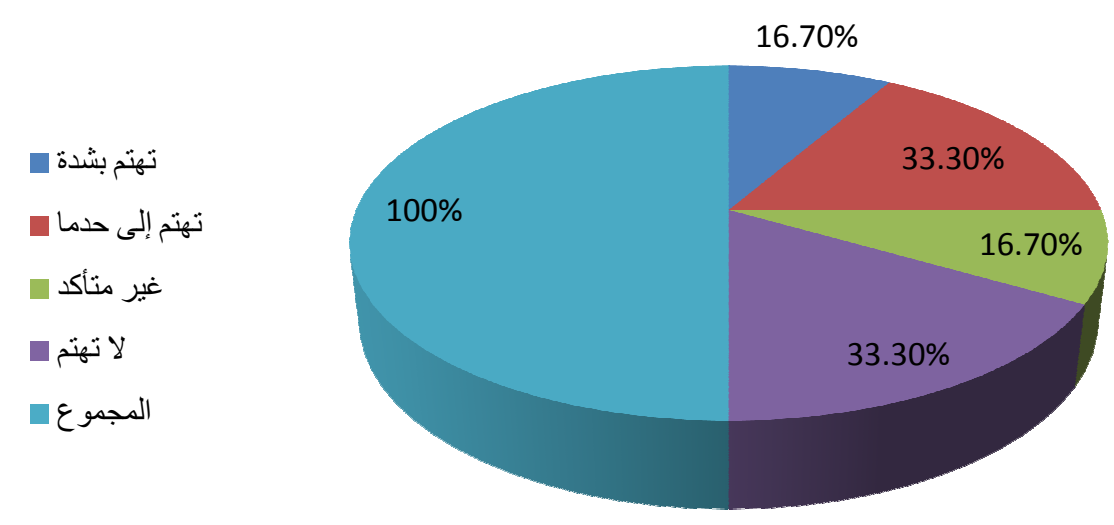


د. أخم إسماعبله حسبن

من الجدول والثكل رقم(4) يتضح أن 33.3\% من المبحوثين يرون أن البرامج الاينية بالفضائيات العربية تهنم إلى حد ما بتوعية الحجاج وتدريبهم على مناسك الحج،ونفس النسبة من المبحوثين يرون أنها لا تهتم بذلك، وغير المتأكدين بلغت نسبتهم 16.7\%، وبنفس هذه النسبة جاء من يرون أنها لا تهنم، وبقراءة تحليلية لهذه النسب يتضح أن البرامج الدينية بالفضائيات العربية لا زالت بعيدة عن الاهتمام الكافي بتوعية الحجاج وتدريبهم تدريباً نوعياً على أداء مناسك الحج. جدول رقم (5) يوضح آراء المبحوثين حول الشكل الأنسب

لتدريب الحجاج على مناسك الحج من خلال البرامج التلفزيونية.

\begin{tabular}{|c|c|c|}
\hline النسبة المئوية & التكرار & الشكل الببامجي الأنسب \\
\hline$\% 6.7$ & 4 & برامج حوارية وشرح \\
\hline$\% 66.6$ & 40 & برامج تثثيل درامي \\
\hline$\% 6.7$ & 4 & برامج قصصية \\
\hline$\% 20$ & 12 & محاكاة بـالمجسمات \\
\hline$\% 00$ & 00 & أخرى \\
\hline$\% 100$ & 60 & المجموع \\
\hline
\end{tabular}

شكل رقم (5) يوضتح آراء المبحوثين حول الثكل البرامجي

التلفزيوني الأنسب لتدريب الحجاج على مناسك الحج.

\section{النسبة المئوية للثكل البرامجي الأنسب}

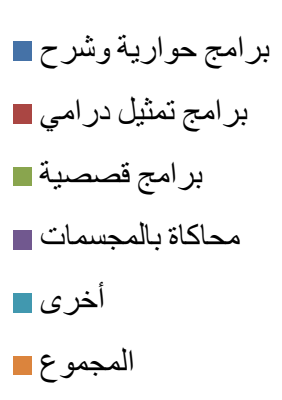

بر امج حوارية وسرح

بر امج قصصية

محاكاة بالمجسمات

أخرى

المجموع

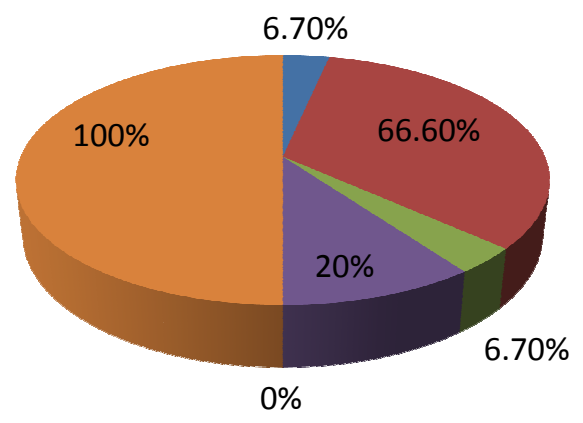

العدد السادس 1442هـ - ديسمبر 2020م

258

جامعة أم درمان الإسلامية مجلة علوم الاتصال 
من الجدول والثكل رقم(5) يتضح أن الغالبية العظمى من المبحوثين يرون أن

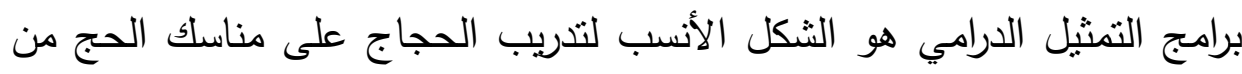

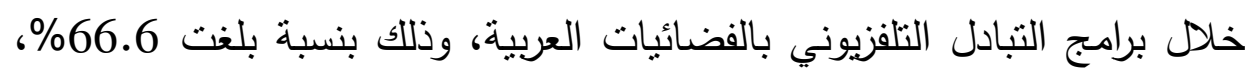

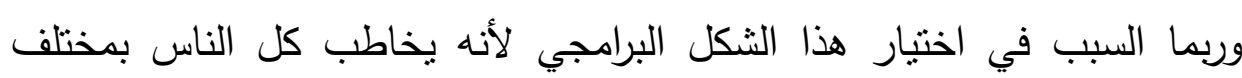

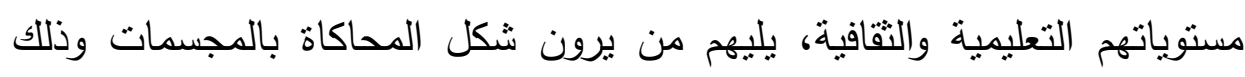

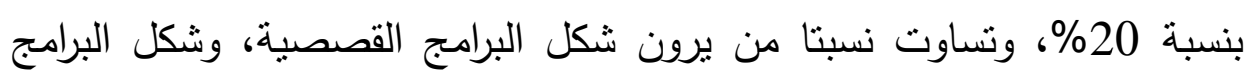
الحوارية بنسبة 6.7\% لكل منهما.

جدول رقم (6) يوضح آراء المبحوثين حول التوقيت الأنسب لبث تلك البرامج.

\begin{tabular}{|c|c|c|}
\hline النسبة المئوية & 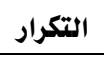 & التوقيت الأنسب للبث \\
\hline$\% 16.7$ & 10 & طيلة الدورة البرامجية السنوية \\
\hline$\% 40$ & 24 & خلال الدورة الببرامجية الفصلية \\
\hline$\% 40$ & 24 & قبيل بداية المناسك \\
\hline$\% 3.3$ & 2 & 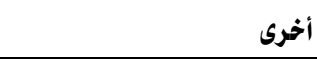 \\
\hline$\% 100$ & 60 & المجموع \\
\hline
\end{tabular}

شكل رقم (6) يوضح آراء المبحوثين حول التوقيت الأنسب لبث تلك البرامج.

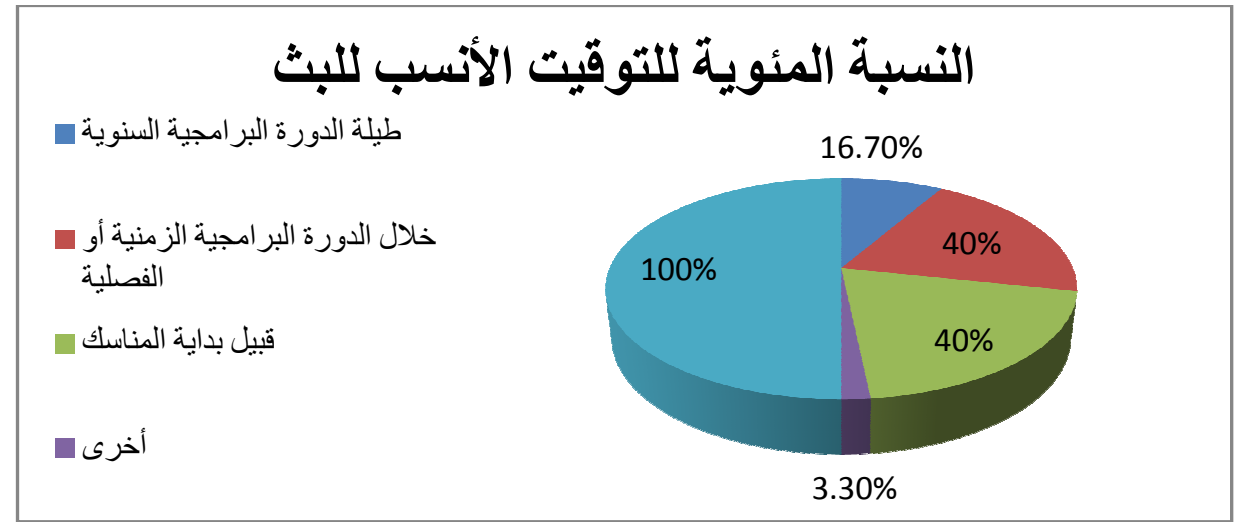

الجدول والثنكل رقم (6) يبينان أن من يرون التوقيت الأنسب لتلك البرامج هو

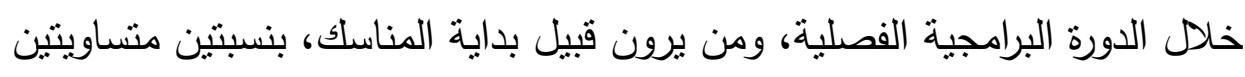


د. أخم إسماعبله حسين

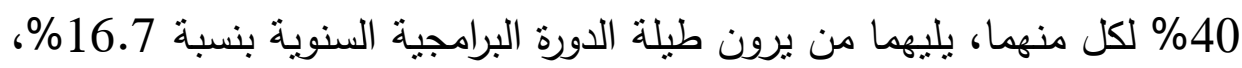

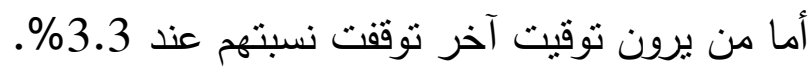
جدول رقم (7) يوضح رأي المبحوثين حول استخدام أساليب مستحدثة تعزز أثر برامج التبادل التلفزيوني التدريبي على الحجاج.

\begin{tabular}{|c|c|c|}
\hline النسبة المئوية & 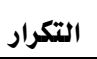 & الأسلوب المستحدث \\
\hline$\% 73$ & 44 & تقديم البرنامج كمقاطع فيديو على الموبايل \\
\hline$\% 10$ & 6 & تقديم البرنامج كمقاطع صوتية على الموبايل \\
\hline$\% 10$ & 6 & تقديم الببرنامج كرسومات على مذكرةورقية \\
\hline$\% 7$ & 4 & 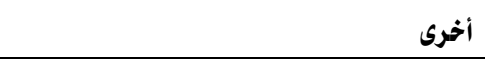 \\
\hline$\% 100$ & 60 & المجموع \\
\hline
\end{tabular}

شكل رقم (7) يوضح أي المبحوثين حول استخدام أساليب مستحدثة

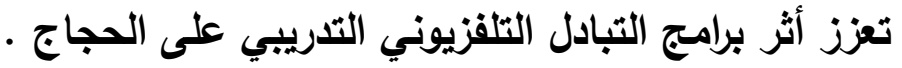

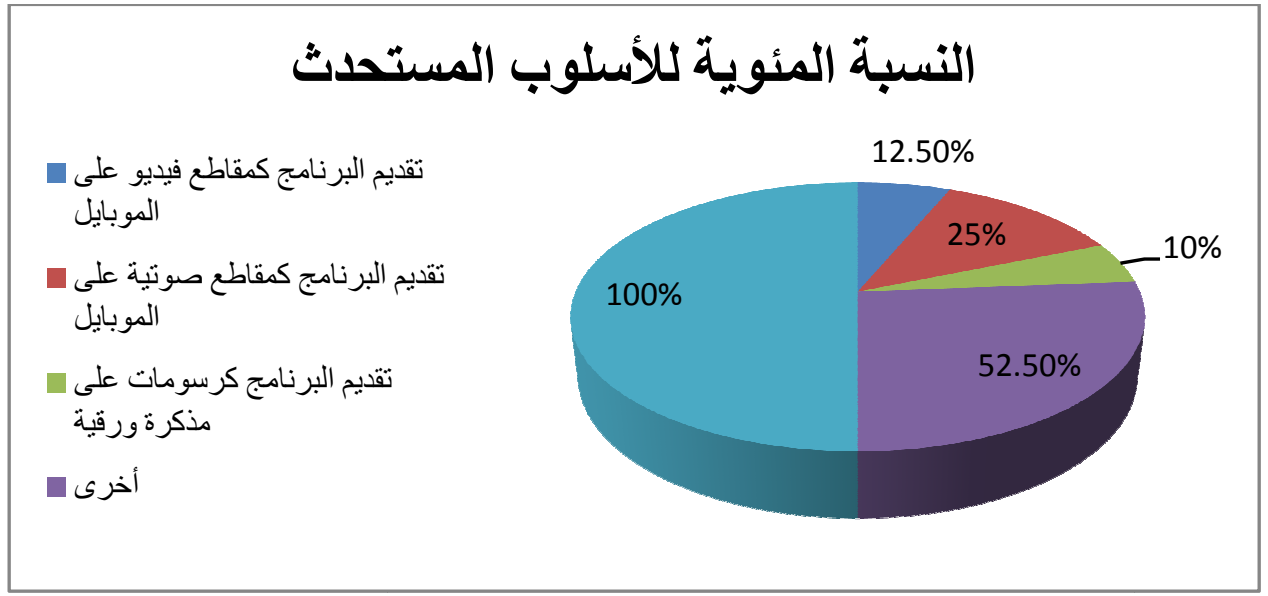

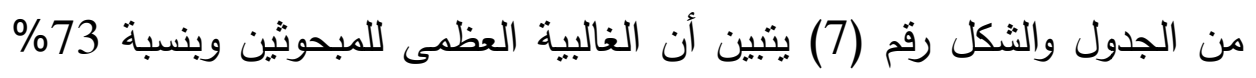

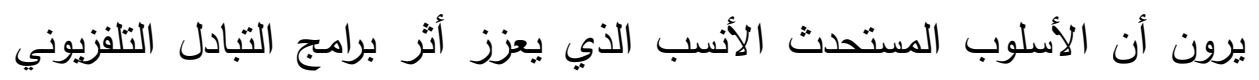

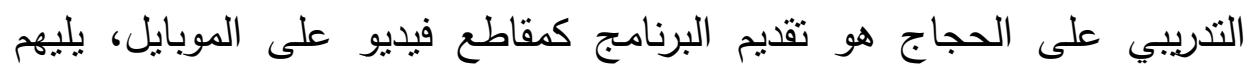

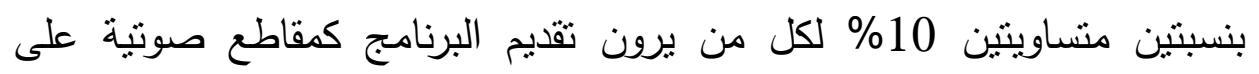


التباده البراجيج التلغزيوني بينه دول العالم الإسلامي

الموبايل، ومن يرون تقديم البرنامج كرسومات على مذكرة ورقية، أما من يرون أساليب أخرى جاءت نسبتهم قليلة 7\%

جدول رقم (8) يوضح موافقة المبحوثين حول جدوى تطبيق فكرة التبادل

البرامجي التلفزيوني الإرشادي والتدريبي بين الفضائيات العربية.

\begin{tabular}{|c|c|c|}
\hline النسبة المئوية & التكرار & مستوى الموافقة \\
\hline$\% 60$ & 36 & أوافق بشدة \\
\hline$\% 30$ & 18 & أوافق \\
\hline$\% 10$ & 6 & غير متأكد \\
\hline$\% 00$ & 0 & غير موافق \\
\hline$\% 100$ & 60 & المجموع \\
\hline
\end{tabular}

شكل رقم (8) يوضح موافقة المبحوثين حول جدوى تطبيق فكرة التبادل

البرامجي التلفزيوني الإرشادي والتدريبي بين الفضائيات العربية.

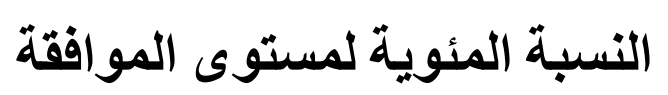

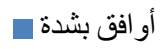

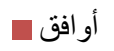

غير متأكد

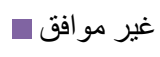

المجموع سير

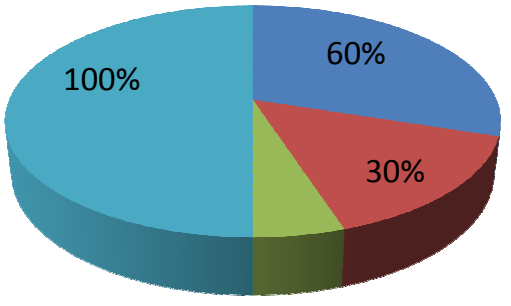

$0 \% \quad 10 \%$

من الجدول والثكل رقم(8) يتبين أن أكثر المبحوثين وبنسبة 60\% يوافقون بشدة على جدوى تطبيق فكرة التبادل البرامجي التلفزيوني الإرشادي والتدرببي بين الفضائيات العربية يليهم من بوافقون على ذلك بنسبة بلغت 30\%، ومجموع هاتين النسبتين يعطي مؤشراً إيجابياً يؤكد نجاح تطبيق هذه الفكرة، وغير المتأكدين نسبتهم قليلة10\% ولا يوجد من بين المبحوثين من لا يوافق على ذلك. 
د. أخر إسماعبله حسين

جدول رقم (9) يوضح رأي المبحوثين حول مميزات

الفكرة كبرنامج تبادل تلفزيوني بين الفضائيات العربية

\begin{tabular}{|c|c|c|}
\hline النسبة المئوية & 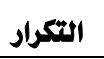 & ميزات الفكرة \\
\hline$\% 15$ & 9 & تقلل تكاليف الإنتاج البرامجي \\
\hline$\% 8.4$ & 5 & تدفع إلى تجويد الإتتاج وأسلوب العرض \\
\hline$\% 13.3$ & 8 & تجد اللدعم والتمويل من عدة جهات \\
\hline$\% 20$ & 12 & خلق نوع من التكامل بين الفضائيات العربية \\
\hline$\% 13.3$ & 8 & توحيد الوجدان العربي والمسلم \\
\hline$\% 30$ & 18 & كل ما ذكر \\
\hline$\% 00$ & 0 & 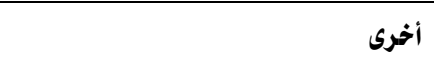 \\
\hline$\% 100$ & 60 & المجموع \\
\hline
\end{tabular}

شكل رقم (9) يوضح رأي المبحوثين حول مميزات

الفكرة كبرنامج تبادل تلفزيوني بين الفضائيات العربية

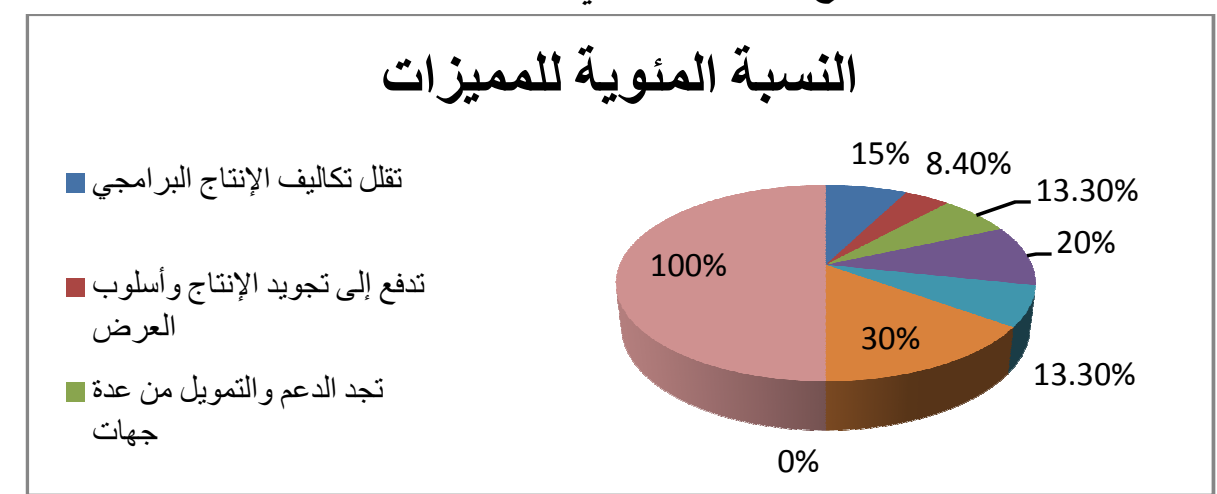

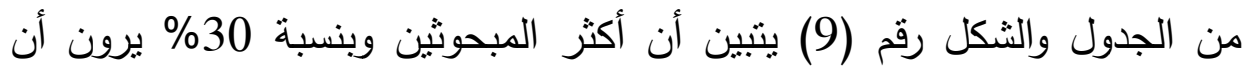

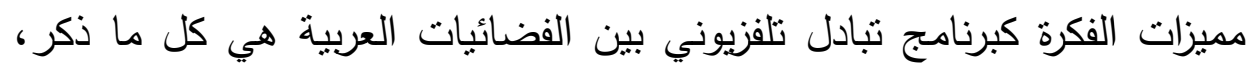

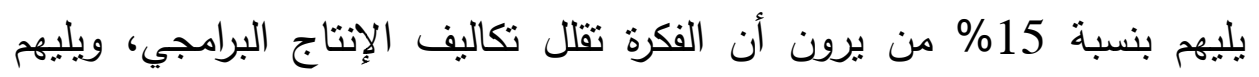

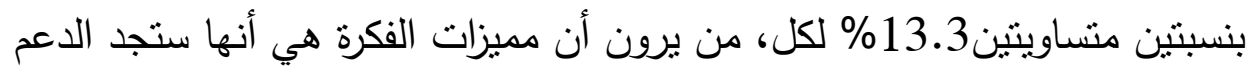

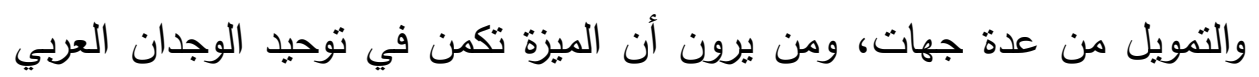

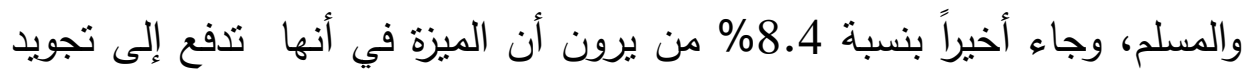

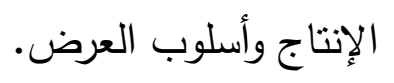


النتائج والتوصيات:

أولاً: نتائج الاراسة:

1- أوضحت الدراسة أن المبحوثين يتابعون البرامج الدينية بالقنوات الفضائية العربية باستمرار -

2- بينت الدراسة أن المبحوثثن منقسمين في آرائهم بين اهتمام البرامج الدينية

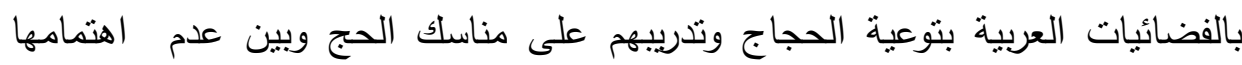
بذلك.

3- أكدت الدراسة أن برامج التمثيل الدرامي هي الثكل الأنسب لتدريب الحجاج على مناسك الحج من خلال برامج التبادل التلفزيونيبالفضائيات العربية. 4- أبانت الدراسة أن التوقيت الأنسب لبث تلأك البرامج هو خلادل الدورة البرامجية

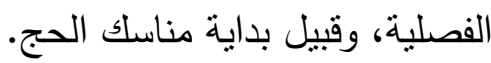
5- أوضحت الدراسة أن الأسلوب المستحدث المناسب الذي يعزز أثز برامج التبادل التلفزيوني التدربيية على الحجاج هو تقديم البرنامج كمقاطع فيديو على الموبايل.

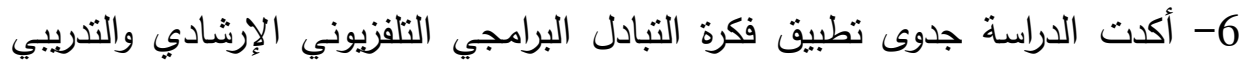
بين الفضائيات العربية. 7- أكدت الدراسة أن مميزات الفكرة كبرنامج تبادل تلفزيوني بين الفضائيات العربية هي

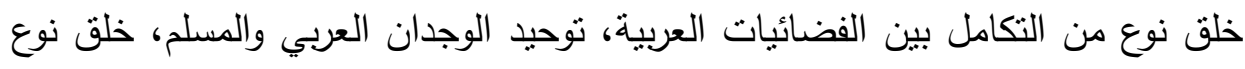

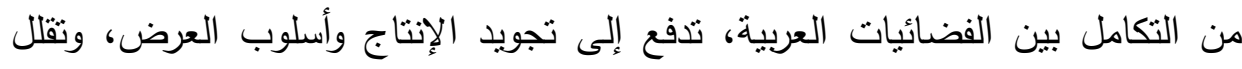
تكاليف الإنتاج البرامجي.

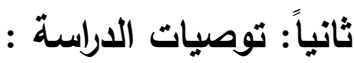
1- على الفضائيات العربية أن تولي اهتماما كبيراً لتوعية الحجاج وتدريبهم على مناسك تواتك الحج من خلال برامج التبادل التلفزيوني المتخصصة انوب الثيات فيما بينها. 2- ضرورة تقديم برامج إرشاد وتدريب الحجاج بأساليب شيقة وجاذبة وسهلة الفهم والاستيعاب بالنسبة للجميع. 3- أهمية أن تتضمن الدورة البرامجية التي تسبق موسم الحج هذا النوع من البرامج النوعية والمتخصصة. 4- بعد تقديم هذه البرامج على الفضائيات العربية يجب تعزيز أنزها من خلال إعدادها في شكل مقاطع فيديو تملك للحجاج في هواتفهم المحمولة. 


\section{د. أخمد إسماعبل حسين}

5- ضرورة تبادل هذه البرامج بين الفضائيات العربية لما يحققه من فوائد ومكاسب

مباشرة للفضائيات نفسها.

قائمة المصادر والمراجع:

1 - 2 - سورة البقرة ، الآية 158

2- 2 - 2 - سورة البقرة ، الآية 189

37،96،98، سورة البقرة ، الآيات

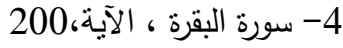

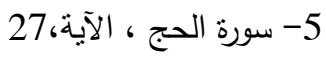

6- - سورة آل عمران ، الآية 97

7- رجاء محمود أبوعلام، مناهج الآية والبحث في العلوم النفسية والتربوية،القاهرة،دار النشر

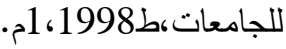

8- محمد الصاوي محمد المبارك ، البحث العلمي ،أسسه وطريقة كتابته ، القاهرة ،المكتبة الأكاديمية

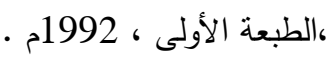

9- عبد الرحمن أحمد عثمان، مناهج البحث العلمي وطرق كتابة الرسائل الجامعية،الخرطوم، دار جامعة

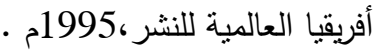

10- مجمع اللغة العربية المعجم الوجيز، التاهرة، دار التحرير للطبع والنشر، 1990، 1980م.

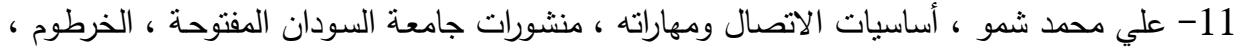

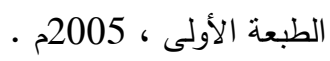

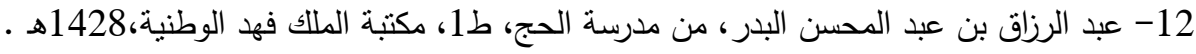

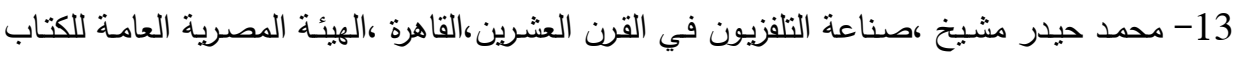
• 1994،

14- محمد بن صالح العثيمين، فقه العبادات، (العقائد،الطهارات، الصلاة، الزكاة، الصوم، الحج؛) ،

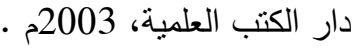

https://mawdoo3.com-15 https://sudanjem.com/2014/04 -16 http://www.sudanile.com/102934 -17 الموقع الرسمى لإتحاد إذاعات الدول العربية http://www.asbu.net -18 http://www.asbucenter.dz/apps/a_web/en/asbucenter-activities.html-19 http://www.articles. islamweb.net -20 